\title{
Association of anxiety with perception of histamine induced bronchoconstriction in patients with asthma
}

Philip Spinhoven, Anke S van Peski-Oosterbaan, A J Willem Van der Does, Luuk N A Willems, Peter J Sterk

\begin{abstract}
Background - The perception of bronchoconstriction varies among patients with asthma and this perception may be related to the covariation of sensory and affective aspects of dyspnoea. A study was performed to evaluate whether there are differences in the perception of histamine induced bronchoconstriction between anxious and non-anxious perceivers and whether anxious perception of bronchoconstriction can be predicted by higher levels of baseline anxiety.

Methods - Seventy eight asthmatic subjects referred for a histamine challenge test undertook baseline measures for anxiety symptomatology and forced expiratory volume in one second $\left(\mathrm{FEV}_{1}\right)$ followed by perceived breathlessness (Borg scale), anxiety (SUDS), and $\mathrm{FEV}_{1}$ measurement before and during induced bronchoconstriction. Based on the correlation between Borg and SUDS scores, the patients were divided into anxious and non-anxious perceivers.

Results - Forty one patients reported no anxiety during the challenge test. The anxious perceivers $(n=20)$ had higher levels of perceived breathlessness and anxiety at $20 \%$ fall in $\mathrm{FEV}_{1}$ and were more accurate in their perception of airways obstruction than non-anxious perceivers $(n=58)$. However, they did not report higher baseline levels of anxiety symptomatology.

Conclusions - Anxiety experienced during bronchial challenge testing may result from the accurate perception of physiological changes and further direct attention to airways obstruction.

(Thorax 1997;52:149-152)
\end{abstract}

Keywords: anxiety, asthma, dyspnoea.

Variability exists between individuals in perceived dyspnoea for a given degree of bronchoconstriction. ${ }^{1}$ Studies investigating individual differences in dyspnoea in relation to level of anxiety experienced during airways obstruction have yielded equivocal results. The frequency of retrospectively reported panictype symptoms during typical asthmatic attacks was found to be related to a more positive medical outcome. ${ }^{23}$ However, in a more recent study no significant association was observed between level of anxiety and breathlessness during a methacholine inhalation test. ${ }^{4}$

Attempts have also been made to relate perception of bronchoconstriction to individual differences in baseline anxiety symptomatology or morbidity with mixed results. In some studies anxious dependent subjects (asthmatic patients as well as normal controls) had significantly greater threshold values for inspiratory and expiratory resistive loads, ${ }^{5-7}$ whereas in another study patients with insensitivity to emotional arousal performed significantly worse on an asthma perception task. ${ }^{8}$

A methodological problem associated with most of the studies into anxiety and perception of bronchoconstriction is that the role of "panic fear" personality or symptomatology ${ }^{3}$ has been investigated which differs from more contemporary psychiatric investigations of anxiety symptoms or disorders. ${ }^{9}$ Moreover, in many studies the perception of physiological changes has been measured in global terms of dyspnoea or breathlessness. However, dyspnoea is not a unidimensional concept but includes sensory and affective components. ${ }^{410}$

This study aimed to explore the perception of induced bronchoconstriction in subjects in whom sensory and affective aspects of dyspnoea were strongly correlated over successive inhalations of histamine (anxious perceivers) and subjects in whom these aspects did not covary (non-anxious perceivers)

\section{Methods}

SUBJECTS

Consecutive referrals to the University Hospital lung function laboratory for a histamine challenge test for clinical diagnosis and follow up participated in the study. Inclusion criteria were a diagnosis of asthma according to American Thoracic Society criteria ${ }^{11}$ and age between 18 and 65 years. Exclusion criteria were admission to hospital and poor Dutch speakers. The study was approved by the University Hospital medical ethics committee.

The response rate to the mailed invitation to participate in the study was $79 \%$. The sample consisted of 78 asthmatic patients (30 men) of mean (SD) age 34.5 (12.4) years and mean duration of asthma 17.4 (12.7) years. Nineteen were smokers and 52 used daily asthma medication (31 bronchodilators, 20 corticosteroids). Fifty six patients used medication during asthma exacerbations (53 bronchodilators). The mean number of previous his- 
Table 1 Mean (SD) descriptive and experimental data of anxious and non-anxious perceivers

\begin{tabular}{lll}
\hline & $\begin{array}{l}\text { Non-anxious perceivers } \\
(n=58)\end{array}$ & $\begin{array}{l}\text { Anxious perceivers } \\
(n=20)\end{array}$ \\
\hline Age (years) & $33.4(12.3)$ & $37.7(12.5)$ \\
M:F & $22: 36$ & $8: 12$ \\
IUATLD & $6.3(2.4)$ & $6.1(3.1)$ \\
History of asthma (years) & $16.7(12.3)$ & $18.8(13.8)$ \\
Daily medication (yes/no) & $40 / 18$ & $15 / 5$ \\
Smoking (yes/no) & $11 / 47$ & 5.13 \\
Previous challenges (n) & $5.8(1.7)$ & $0.81(0.06-8.0)$ \\
Median (range) PC $_{20}$ (mg/ml) & $0.89(0.03-8.0)$ & $93.0(26.3)$ \\
FEV (\% predicted) & $90.8(14.9)$ & $3 / 17$ \\
Panic disorder (yes/no) & $7 / 51$ & $16.0(14-45)$ \\
ACQ (median, range) & $15.5(14-29)$ & $23.0(17-53)$ \\
BSQ (median, range) & $21.0(17-48)$ & $39.5(25-69)$ \\
STAI-X2 (median, range) & $37.5(22-58)$ & $36.5(22-58)$ \\
SDS (median, range) & $34.0(22-53)$ & \\
\hline
\end{tabular}

IUATLD $=$ International Unit against Tuberculosis and Lung Disease questionnaire; $\mathrm{PC}_{20}=$ provocative concentration of histamine to cause a $20 \%$ fall in $\mathrm{FEV}_{1} ; \mathrm{FEV}_{1}=$ forced expiratory volume in one second; $\mathrm{ACQ}=$ Agoraphobic Cognitions Questionnaire; $\mathrm{BSQ}=$ Body Sensations Questionnaire; STAI-X2 = trait subscale of State-Trait Anxiety Inventory; SDS=Self-Rating Depression Scale.

tamine challenges was 5.7 (1.7) and mean baseline forced expiratory volume in one second $\left(\mathrm{FEV}_{1}\right)$ was $91.3 \%$ predicted. The median concentration of histamine provoking a fall in $\mathrm{FEV}_{1}$ of $20 \%\left(\mathrm{PC}_{20}\right)$ was $0.89 \mathrm{mg} / \mathrm{ml}$ (range $0.06-8.0)$.

STUDY DESIGN

Subjects completed questionnaires on baseline anxiety characteristics and then undertook a histamine inhalation challenge test. $^{12}$ Immediately before the $\mathrm{FEV}_{1}$ measurements, perceived breathlessness and level of anxiety were measured.

Baseline anxiety assessment

Anxiety symptomatology was measured using several measures: (1) the International Union Against Tuberculosis and Lung Disease questionnaire (IUATLD) ${ }^{13}$ to assess the occurrence of 12 respiratory symptoms during the previous 12 months; (2) the Anxiety Disorders Interview Schedule (Revised) (ADIS-R), ${ }^{14}$ a structured psychiatric interview protocol for diagnosing panic disorder; ${ }^{9}$ (3) the Body Sensations Questionnaire $(\mathrm{BSQ})^{15}$ to measure the degree to which subjects fear somatic sensations commonly associated with panic and the Agoraphobic Cognitions Questionnaire (ACQ) to assess the inclination to misinterpret bodily sensations catastrophically; (4) the State-Trait Anxiety Inventory (STAI) ${ }^{16}$ which measures generalised anxiety; and (5) the Self-Rating Depression Scale (SDS) ${ }^{17}$ which measures the degree of depression.

Assessment during induced bronchoconstriction The Borg scale ${ }^{18}$ was used to measure perceived breathlessness and the Subjective Units of Distress Scale (SUDS) ${ }^{19}$ to measure the level of anxiety during the induction of bronchoconstriction.

$\mathrm{FEV}_{1}$ was measured with a dry rolling seal spirometer (Morgan Spiroflow, UK) according to a standardised procedure. ${ }^{20}$ Baseline $\mathrm{FEV}_{1}$ was expressed as the percentage of the predicted value. ${ }^{19}$ Inhalations of histamine were continued until the $\mathrm{FEV}_{1}$ had fallen by $20 \%$ or more from baseline or the maximum concentration of $8 \mathrm{mg} / \mathrm{ml}$ was reached. Bronchial responsiveness was expressed as the provocative concentration of histamine causing a $20 \%$ fall in $\mathrm{FEV}_{1}$ from baseline. This was obtained from the log dose-response curve by $\log$ linear interpolation of the last two points. ${ }^{12}$

\section{DATA ANALYSIS}

Non-parametric analyses were used as the values of most variables were not normally distributed. The within subject Spearman rank correlation coefficient between Borg and SUDS scores was taken as an index of the degree of anxiety of perceived breathlessness and was used to categorise subjects as anxious and nonanxious perceivers of bronchoconstriction. A rho value of 0.7 was chosen as the limit for the separation of anxious and non-anxious perceivers of airway obstruction - that is, in anxious perceivers anxiety and perceived breathlessness are strongly associated. The correlation between Borg scale and $\mathrm{FEV}_{1}$ scores was used as an index of the accuracy of the perception of airways obstruction. A correlation of 0.7 was used as the limit for the separation of good perceivers and bad perceivers. ${ }^{21}$ The characteristics of anxious and non-anxious perceivers were compared by Mann-Whitney U tests or $\chi^{2}$ analyses as appropriate. $p$ values (two tailed) of $<0.05$ were considered statistically significant.

\section{Results}

The mean within subject correlation between $\mathrm{FEV}_{1}$ values in litres and Borg scale scores was relatively strong $(\mathrm{rho}=-0.76(0.27))$. Forty one patients $(53 \%)$ reported no anxiety (SUDS) during the challenge test. With the chosen threshold (rho $=0.7$ ) 20 of the 78 subjects $(26 \%)$ were classified as anxious perceivers and $58(74 \%)$ as non-anxious perceivers. Moreover, using a threshold of rho $=-0.7,53$ of the 78 subjects $(68 \%)$ were classified as good perceivers and $25(32 \%)$ as bad perceivers of airways obstruction.

There was no significant difference between anxious and non-anxious perceivers with respect to age, sex, respiratory symptoms in daily life, duration of asthma, use of daily medication for asthma, smoking, number of previous challenges, bronchial responsiveness $\left(\mathrm{PC}_{20}\right)$, and predicted baseline $\mathrm{FEV}_{1}$. Moreover, none of the baseline anxiety characteristics (ACQ, BSQ, STAI, SDS, and ADIS-R panic disorder) significantly differed between groups (table 1).

After saline inhalation both groups showed a mean fall in $\mathrm{FEV}_{1}$ of $1 \%$. The fall in $\mathrm{FEV}_{1}$ to the highest histamine concentration of anxious (mean fall from baseline $=28.4(11.6) \%$ ) and non-anxious perceivers (26.5 (9.6)\%) was highly comparable $(p=0.90)$. After inhalation of saline the medians on the Borg scale and SUDS were $0.25 / 5.0$ in the anxious perceivers and $0.5 / 0.5$ in the non-anxious perceivers (both differences not significant). When the $\mathrm{FEV}_{1}$ had fallen $20 \%$ after saline inhalation the me- 
dians on the Borg scale and SUDS were 4.0/ 12.5 in the anxious perceivers and 3.0/4.0 in the non-anxious perceivers, indicating significantly higher scores for both dyspnoea and level of anxiety in the group of anxious perceivers (Borg scale $\mathrm{p}<0.05$, SUDS $\mathrm{p}<0.001)$. Moreover, $\chi^{2}$ analysis revealed a significant association between anxiety and accuracy of perceiving. Among the 20 anxious perceivers 17 (85\%) were good perceivers compared with 36 $(62.1 \%)$ of the 58 non-anxious perceivers $(\mathrm{p}<0.05)$.

\section{Discussion}

This study shows that, in an outpatient sample of asthmatic subjects, anxious perceivers of histamine induced airways obstruction manifest higher scores for both perceived breathlessness and level of anxiety at $20 \%$ fall in $\mathrm{FEV}_{1}$. Anxious perceivers are also more likely to be accurate in their perception of induced bronchoconstriction than non-anxious perceivers. The association between anxious and accurate perceiving of airways obstruction may be interpreted in different ways which are not mutually exclusive. It is conceivable that subjects became more anxious because they accurately perceived progressing degrees of airways obstruction. The lack of a significant difference in anxiety at baseline between anxious and non-anxious perceivers is consistent with this hypothesis. On the other hand, it may be hypothesised that evoked anxiety further facilitates vigilance and attention to airways obstruction and results in a more accurate perception of histamine induced bronchoconstriction. This result is consistent with the work of Kinsman and coworkers ${ }^{3}$ who found that retrospective reports of asthma focused anxiety are related to a more positive medical outcome, suggesting a more vigilant stance towards and accurate perception of respiratory symptoms. Because of the correlational nature of our study causal inferences are unwarranted.

However, this finding does not imply a linear relationship between anxiety and accuracy of perception of airways obstruction. It is possible that only mild levels of anxiety are related to accurate perception while the absence of anxiety may be associated with symptom disregard $^{22}$ and very severe anxiety with impairment of attention span and concentration. ${ }^{57}$ The mixed results of previous studies into anxiety and perception of bronchoconstriction $^{4-822}$ may be due to differences between studies in the levels of anxiety of the patients in addition to differences in the methods of measuring anxiety. It will therefore be valuable to analyse the existence of a possible curvilinear association between anxiety and the accuracy of perception in more detail in future studies.

Unexpectedly, we found no significant differences between anxious and non-anxious perceivers with respect to baseline anxiety symptomatology. The induction of bronchoconstriction for at least the fourth time in the safe environment of a hospital where a bronchodilator may be used in case of severe dyspnoea probably prevented the occurrence of higher levels of anxiety.

The scores for the baseline anxiety characteristics (ACQ, BSQ, STAI) which, according to norms for a psychiatric outpatient population, were all below average suggest a relatively low degree of anxiety symptomatology in the present study sample. It could be argued that this is due to observer bias, response bias, and/or selection bias. However, observer bias seems unlikely because in previous studies, also using a structured diagnostic interview, comparable point prevalences for panic disorder have been reported. ${ }^{2324}$ With clinical unstructured interviews much higher prevalence rates have been reported. ${ }^{25}$ Moreover, the rather high response rate of $79.3 \%$ suggests that the investigated sample is representative.

On the other hand, selection bias may preclude generalisation of the present results. All our asthmatic patients were outpatients of a university hospital routinely referred to a lung function laboratory for a histamine challenge test for clinical diagnosis and follow up. Many of the earlier studies which suggested that asthmatic patients have increased anxiety symptomatology were conducted on hospital inpatients ${ }^{26}$ who are likely to have more severe asthma than outpatients. In contrast to inpatients, in subjects with asthma taken from a general population no significant association between anxiety or depression and asthma has been observed. ${ }^{27}$

We conclude that accurate perception of bronchoconstriction may induce mild degrees of anxiety directing attention to airways obstruction. Further research in this area could make use of asthmatic patients with no previous experience with challenge tests. Experimental manipulation of anxiety is necessary to elucidate the direction of the causal relationship between anxiety and accuracy of perception of airways obstruction.

The authors wish to thank A J Beekman, M Compas, J Verkerk, J Dekker, and L Stökl for their assistance with the data collection.

1 Burdon JGW, Juniper EF, Killian KJ, Hargreave FE, Campbell EJM. The perception of breathlessness in asthma. Am Rev Respir Dis 1982;126:825-8.

2 Staudenmayer H, Kinsman RA, Dirks JF, Spector SL, Wangaard C. Medical outcome in asthma patients: effects of airways hyperactivity and symptom-focused anxiety Psychosom Med 1979;41:109-18.

3 Kinsman RA, Dirks JF, Jones NF. Psychomaintenance of chronic physical illness. Clinical assessment of personal styles affecting medical management. In: Millon T, Green C, Meagher R, eds. Handbook of clinical health psychology. New York: Plenum Press, 1982:435-66.

4 Boulet LP, Cournoyer I, Deschesnes F, Leblanc P, Nouwen A. Perception of airflow obstruction and associated breathlessness in normal and asthmatic subjects: correlation with anxiety and bronchodilator needs. Thorax 1994;49: with anxict

5 Hudgel DW, Cooperson DM, Kinsman RA. Recognition of added resistive loads in asthma. The importance of behavioral styles. Am Rev Respir Dis 1982;126:121-5.

6 Hudgel DW, Kinsman RA. Interactions among behavioral style, ventilatory drive, and load recognition. Am Rev style, ventilatory drive, and

7 Tiller J, Pain M, Biddle N. Anxiety disorder and perception of inspiratory resistive loads. Chest 1987;91:547-51.

8 Steiner H, Higgs CMB, Fritz GK, Laszlo G, Harvey JE Defense style and the perception of asthma. Psychosom Med 1987;49:35-44

9 American Psychiatric Association. Diagnostic and statistical manual of mental disorder. 3rd edn, revised. Washington DC: American Psychiatric Association, 1987. 
10 Jones PW. Breathlessness perception in airways obstruction. Eur Respir f 1992;5:1035-6.

11 American Thoracic Society. Standards for the diagnosis and care of patients with chronic obstructive pulmonary disease (COPD) and asthma. Am Rev Respir Dis 1987;136:225-44.

12 Sterk PJ, Fabbri LM, Quanjer PhH, Cockcroft DW, O'Byrne PM, Anderson SD, et al. Airway responsiveness. Standardized challenge testing with pharmacological, physical 6(Suppl 16):53-83.

13 Burney P, Chinn S. Developing a new questionnaire for measuring the prevalence and distribution of asthma. Chest 1987;91:79-83S

14 Di Nardo PA, O'Brien GT, Barlow DH, Waddell MT, Blanchard EB. Reliability of DSM-III anxiety disorder
categories using a new structured interview. Arch Gen categories using a new struc

15 Chambless DL, Caputo GC, Bright P, Gallagher R. Assessment of fear of fear in agoraphobics: the body sensations questionnaire and the agoraphobic cognitions questionnaire. F Consult Clin Psychol 1984;52:1090-7.

16 Spielberger CD, Gorsuch A, Lushene RL. The State-Trait chologist Press, 1970.

17 Zung WWK. A self-rating depression scale. Arch Gen Psychiatry 1965;12:63-70.

18 Borg G. A category scale with ratio properties for intermodal and interindividual comparisons. In: Geissler HG, Petzold P, eds. Psychophysical judgement and the process of perception.
Berlin: VEB Deutscher Verlag der Wissenschaften, 1982: $25-34$.

19 Wolpe J. The practice of behavior therapy. New York: Pergamon Press, 1973.

20 Quanjer PhH, Tammeling GJ, Cotes JE, Pedersen OF, Peslin R. Lung volumes and forced expiratory flows. Eur Respir F 1993;6(Suppl 16):4-39.

21 Peiffer C, Marsac J, Lockhart A. Chronobiological study of the relationship between dyspnoea and airway obstruction in symptomatic asthmatic subjects. Clin Sci 1989;77:23744 .

22 Burney PGJ, Luczynska C, Chinn S, Jarvis D, for the European Community Respiratory Health Survey. The European Community Respiratory Health Survey. Eur Respir 7 1994;7:954-60.

23 Shavitt RG, Gentil V, Mandetta R. The association of panic/ agoraphobia and asthma: contributing factors and clinical implications. Gen Hosp Psychiatry 1992;14:420-3.

24 Karajgi B, Rifkin A, Doddi S, Kolli R. The prevalence of anxiety disorders in patients with chronic obstructive pulmonary disease. Am F Psychiatry 1990;147:200-1.

25 Yellowees PM, Alpers JH, Bowden JJ, Bryant GD, Ruffin
RE. Psychiatric morbidity in patients with chronic airflow obstruction. Med F Aust 1987;146:305-7.

26 Lehrer PM, Isenberg S, Hochron SM. Asthma and emotion: a review. I Asthma 1993;30:5-21.

27 Janson C, Bjornsson E, Hetta J, Boman G. Anxiety and depression in relation to respiratory symptoms and asthma. Am $\mathcal{F}$ Respir Crit Care Med 1994;149:930-4. 